\title{
Quantifying early diabetic retinopathy
}

\author{
J. R. Howard-Williams ${ }^{1}$, C.O.Peckar ${ }^{2}$, R. R. Holman ${ }^{3}$, R. C. Turner ${ }^{3}$ and A.J. Bron ${ }^{1}$ \\ ${ }^{1}$ Nuffield Laboratory of Ophthalmology, Oxford Eye Hospital, Oxford, \\ ${ }^{2}$ Warrington District General Hospital, Warrington and \\ ${ }^{3}$ Diabetes Research Laboratories, Nuffield Department of Clinical Medicine, Radcliffe Infirmary, Oxford, UK
}

Summary. A precise and accurate method of numerically quantifying diabetic retinopathy, on standardised retinal colour photographs, has been developed which allows small changes and trends to be monitored. Colour slides are projected onto a screen and features noted on an acetate sheet which provides a permanent record. Sector analysis showed microaneurysms and haemorrhages to occur most often at the temporal-to-macula area, exudates at the macula and cotton wool spots on the nasal side of the retina. Seventy percent of microaneurysms appeared in the previous year, irrespective of the severity of the retinopathy. In proportion to their usual relative prevalences, after normalisation of distribution, the various features can be combined to provide a single value, the Retinopathy Index. This provides an overall assessment of retinopathy which is suitable for comparing the progress of mild retinopathy in prospective studies.

Key words: Quantitation, diabetic retinopathy, retinal photographs, retinopathy index.
The ability to detect small changes in background retinopathy over a relatively short period of time can be a problem when using discontinuous grading systems such as the Airlie House and Hammersmith systems [1, 2], based on comparisons with reference photographs. Counting individual retinal features provides a more precise continuous scale of measurement. The relative weighting of different features has been controversial, but their statistical interdependence can be used to provide a single overall assessment. A method of analysis has been devised to monitor small changes in mild background retinopathy in a relatively small group of patients.

The method is illustrated in a 2-year study [3] of 69 Type 1 (insulin-dependent) diabetic patients, found on screening to have background retinopathy, in which retinal photographs were taken at yearly intervals. The different retinopathic features were analysed separately and combined to produce a single, descriptive Retinopathy Index which can be used for statistical analyses comparing different patients.

\section{Materials and methods}

Using a Zeiss Oberkochen 30 degree field retinal fundus camera, eight standardised overlapping fields, linear magnification $\times 2.5$ were taken of each eye. Every field was photographed twice with refocussing in between to ensure a clear image. The fields photographed were four horizontal (optic disc, nasal-to-disc, macula and temporal-to-macula) and four diagonal (superior temporal, superior nasal, inferior nasal and inferior temporal) (Fig. 1).

For the disc and macula fields the eyepiece graticule was centered on the structure concerned, whilst for the nasal-to-disc view the temporal edge of the field was arranged so as to bisect the disc. For the

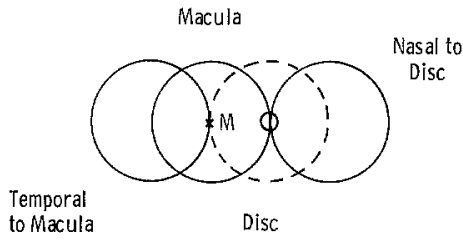

The four Horizontal Fields

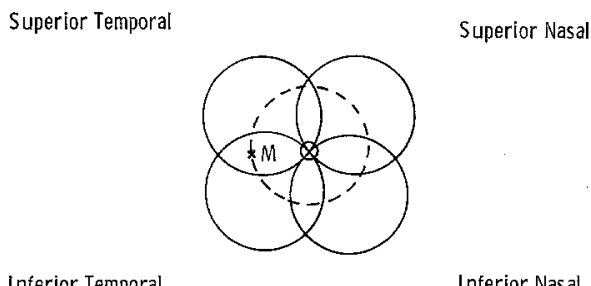

Inferior Temporal

Inferior Nasal

\section{The four Diaqonal Fields}

Fig. 1. Representation, for the right eye, of the four horizontal and four diagonal fields which were routinely photographed 


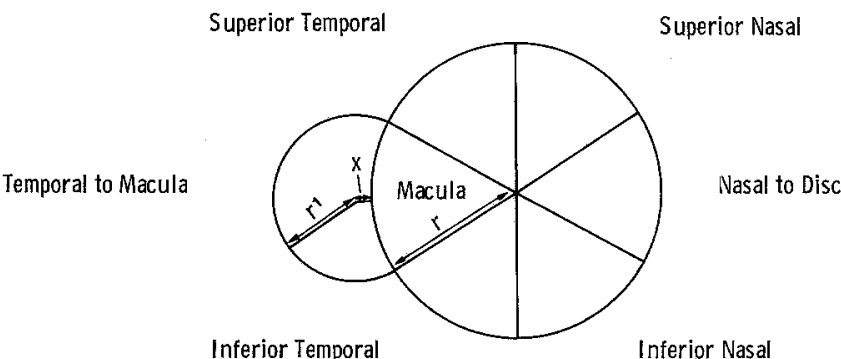

Fig. 2. Example of the scored grid used, on the acetate montage, to define the seven retinal sectors analysed in each eye. $r=$ radius of large circle $(177 \mathrm{~mm}), r^{1}=$ radius of small circle $(94 \mathrm{~mm})$ and $\times$ the distance between the centre of the small circle and the edge of large circle $(5.5 \mathrm{~mm})$

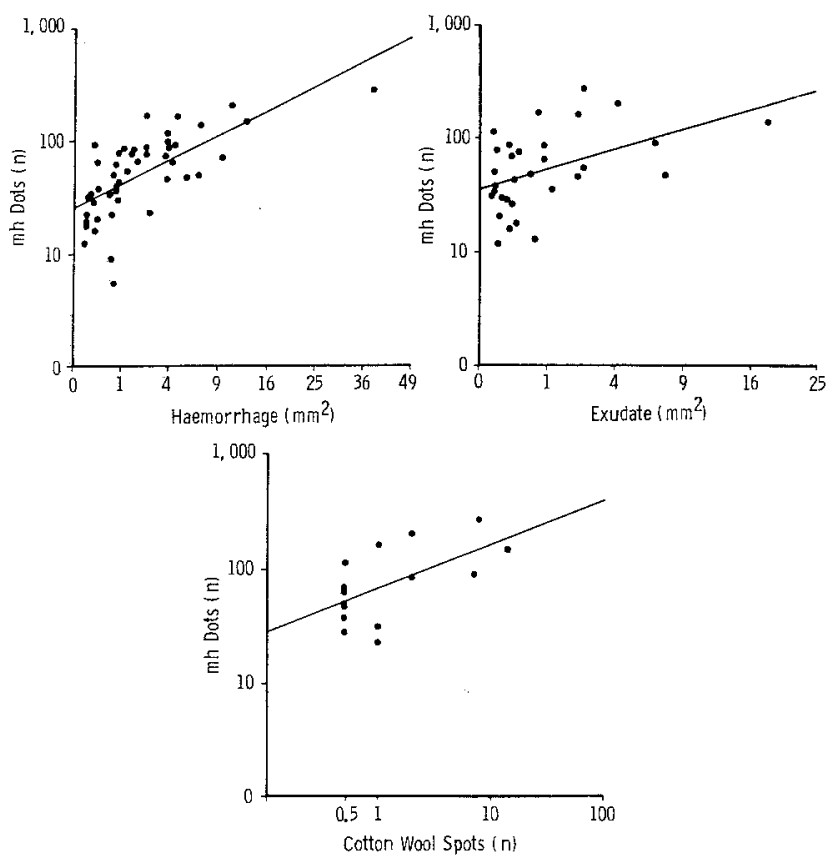

Fig.3. Interdependence of retinopathic features using the information obtained for all patients at entry to the study. The microaneurysm count was compared with the area of haemorrhage, the area of exudate and the numbers of cotton wool spots. The data was transformed to obtain a more normal distribution by taking the common logarithm of counts and square root of areas. Least squares regression analysis was used to express the relationship with microaneurysm counts, shown on the ordinate, and haemorrhage, exudate and cotton wool spots shown on the abscissa

temporal-to-macula view the nasal edge just incorporated the macula. For the diagonal views the field bisected the disc in each of the four meridional positions at $1.30,4.30,7.30$ and 10.30 o'clock. Changing the field was achieved by moving the fixation target viewed by the other eye.

The colour slides (Kodak Ektachrome 64 reversal film) from each eye were back-projected in turn onto a ground glass screen and overlaid by an $\mathrm{A} 2$ acetate sheet so as to produce a montage of the posterior retinal pole with an additional magnification of $\times 10$ (ie $\times 25$ total magnification). This was occasionally checked by projecting a graticule onto the acetate sheet.

The disc was projected onto the acetate sheet and a fine fibretipped red pen used to outline the disc and the midline of the major retinal blood vessels. Next, the field nasal to the disc was projected and the acetate sheet shifted on the screen to align the retinal blood vessels drawn with those projected. The procedure was then repeated for the remaining six fields.

Five features, namely microaneurysms, cotton wool spots, areas of haemorrhage, areas of exudate and new vessels were systematically traced onto the acetate using for each feature different coloured alcohol soluble ink fibre-tip pens.

Sample reference slides were used to train new observers in the method. These slides indicate how separate features should be quantified, including definite and indefinite features. Where blurring or density make classification difficult, the lesion is annotated as nonquantifiable. Intra-retinal microvascular abnormalities were also annotated [4].

With the retinal montage completed, a standard seven-sectored grid, centred on the disc, was drawn on the acetate sheet (Fig. 2), the $177 \mathrm{~mm}$ radius of the larger circle (r) giving a 46 degree field and the smaller circle having a radius $\left(\mathrm{r}^{1}\right)$ of $94 \mathrm{~mm}$ centered $5.5 \mathrm{~mm}$ from the larger circle on the horizontal axis. The overlapping fields giving a subtended angle in the horizontal meridian of $60^{\circ}$ while retaining the resolution of the $30^{\circ}$ camera. Using wide angle photography, i.e. a $45^{\circ}$ or $60^{\circ}$ camera, less photographs would be needed, but the lesser definition does not allow precise quantitation. The seven equal quantifiable areas of the grid totalled $1,148 \mathrm{~mm}^{2}$ equivalent to $184 \mathrm{~mm}^{2}$ retina or $17 \%$ of the total retinal area (circa $1100 \mathrm{~mm}^{2}$ ) [4].

All red features of $6 \mathrm{~mm}^{2}(110 \mu$ diameter on the retina) or less [5-8], as measured by a standard template, were designated as microaneurysm/haemorrhage $(\mathrm{mh})$ dots since it is impossible to distinguish between microaneurysms and small round haemorrhages of this size on colour photographs. Total numbers of $\mathrm{mh}$ dots for each sector and the eye as a whole were noted. In subsequent years, overlaying acetate sheets from the previous year allowed changes to be readily visualised; in particular the mh dots could be identified as "old events" being present the previous year or as new events. To allow for minor photographic displacement, a movement of $4 \mathrm{~mm}$ on the acetate sheet was necessary to accept a lesion as a new event.

The perimeter of any retinal haemorrhage or hard exudate was traced using a computerised MOP AMO3 planimeter giving an automatic readout of area. Individual hard exudates smaller than $110 \mu$ diameter were ignored; this would exclude most drusen. In an area of multiple small exudates close together, the whole area was measured. The numbers of cotton wool spots and new vessel complexes were counted by sector. Additional features such as capillary loops, drusen, intraretinal microvascular abnormalities and venous beading were also noted. Drusen were identified by their size limit, clinical appearance and failure to progress with time when previous photographs were available. Stereoscopic photographs can be used for the additional identification of drusen or macular oedema. The time taken to draw each montage from 8 photographic views is $15-30 \mathrm{~min}$, depending on the retinopathy present, and another $15-30 \mathrm{~min}$ is required for measuring and counting the features and recording data. The main cost involved is the photographic materials, acetate sheets and pens. The method could be adapted to a computerised system.

In order to obtain a single measure of diabetic retinopathy that could be used in statistical analysis, the numbers of microaneurysms $(\mathrm{mh})$ and cotton wool spots (cws), and the areas of haemorrhage (hm) and hard exudate (ex) were combined as a Retinopathy Index (RI). New vessels were not included in the RI, as the RI is designed to examine the effects of intervention on pre-proliferative diabetic retinopathy. A near normal distribution for each variable was first obtained by taking the common logarithm of the counts and the square root of the areas. Least squares linear regression analysis was then used to express each variable in terms of "microaneurysm equivalents" (Fig. 3). The use of the normal inter-relationship between features means that each is accordingly weighted in the index, e.g. one cotton wool spot is equal to 70 microaneurysms.

The Retinopathy Index is given by the mean of the four values and may be expressed as:

$\mathrm{RI}=\frac{\left(\log _{10} \mathrm{mh}+0.38 \log _{10} \mathrm{cws}+0.21 / \mathrm{hm}+0.17 / \mathrm{ex}+4.8\right)}{4}$

Should any feature be absent, a microaneurysm equivalent of zero is used in its place. No provision was made for scoring new vessel for- 
Table 1. The validation results of four observers (I, II, III and IV) for the microaneurysm count of six sample reference slides of patients A-F. The mean microaneurysms count for each patient is the mean of six weekly counts and the intraobserver coefficient of variation (CV). The final column (ALL) gives the mean microaneurysm count for all observers (i. e. of 24 counts) for each patient and the interobserver coefficient of variation

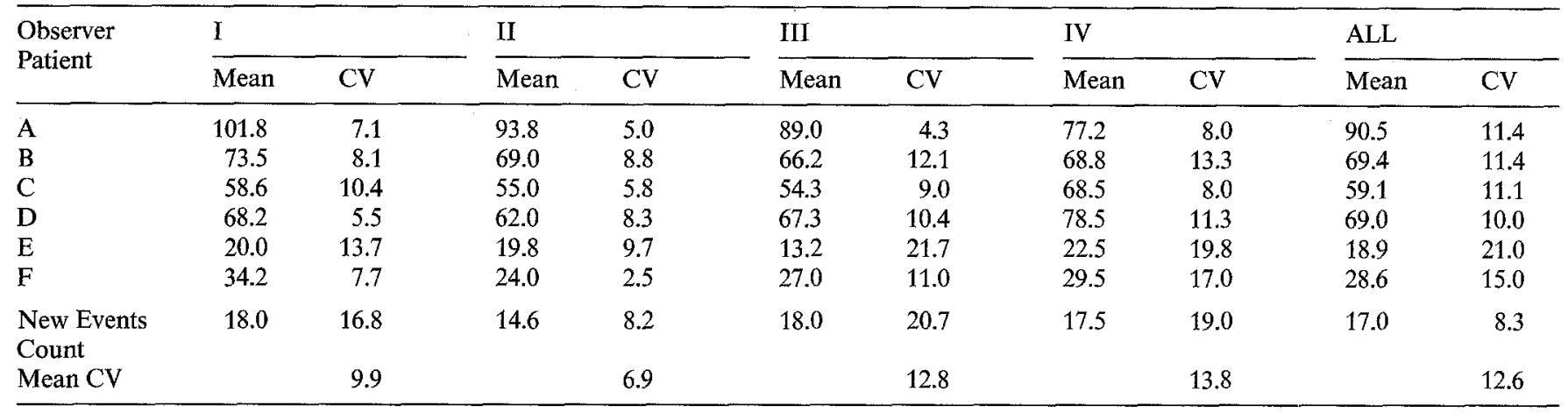

Table 2. The validation results of three observers (I, III and IV) for haemorrhage area $\left(\mathrm{mm}^{2}\right)$ of four sample reference slides of patients A-D. The mean haemorrhage area for each patient is the mean of six weekly counts and the intraobserver and interobserver coefficient of variation

\begin{tabular}{|c|c|c|c|c|c|c|c|c|}
\hline \multirow{2}{*}{$\begin{array}{l}\text { Observer } \\
\text { Patient }\end{array}$} & \multicolumn{2}{|l|}{ I } & \multicolumn{2}{|l|}{ III } & \multicolumn{2}{|l|}{ IV } & \multicolumn{2}{|l|}{ ALL } \\
\hline & $\overline{\text { Mean }}\left(\mathrm{mm}^{2}\right)$ & $\mathrm{CV}$ & Mean $\left(\mathrm{mm}^{2}\right)$ & $\mathrm{CV}$ & Mean $\left(\mathrm{mm}^{2}\right)$ & $\mathrm{CV}$ & Mean & $\mathrm{CV}$ \\
\hline A & 0.95 & 24 & 1.01 & 30 & 0.71 & 60 & 0.89 & 18 \\
\hline $\mathrm{C}$ & 0.62 & 38 & 1.18 & 29 & 1.34 & 29 & 1.05 & 29 \\
\hline D & 0.94 & 23 & 2.03 & 62 & 2.26 & 28 & 1.74 & 33 \\
\hline Mean CV & & 25 & & 39 & & 35 & & 32 \\
\hline
\end{tabular}

Table 3. The validation results of three observers (I, III and IV) for exudate area $\left(\mathrm{mm}^{2}\right)$ of two sample reference slides of patients D and E. The mean exudate area for each patient is the mean of six weekly counts and the intraobserver and interobserver coefficient of variation

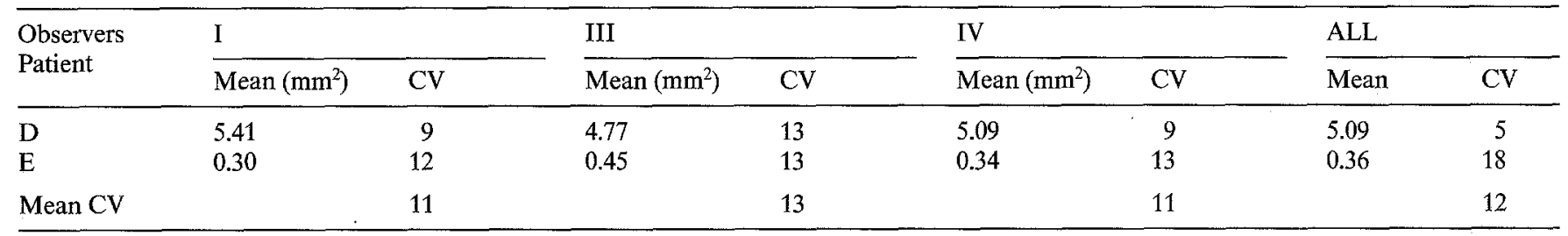

mation, since these patients were recruited only if they had background retinopathy. The index provides an overall measurement of retinopathy, but each feature can still be followed over time separately and the time course for the development of cotton wool spots, IRMA, etc. noted.

The method was validated by asking four observers to quantify six complete sets of fundus transparencies from different patients with varying degrees of retinopathy. Each set, with identification removed, was read weekly for 6 weeks. There is always a possibility of recognition of a fundus photograph, but in view of the complexity of documentation and numbers of lesions for examination, it was thought unlikely that this would lead to any significant bias. Sixty-nine insulin-dependent diabetic patients, attending a routine clinic and found to have background retinopathy on screening, were studied [3]. Retinal photographs were taken initially and then at one and two years.

\section{Results}

The intra and interobserver coefficient of variation for microaneurysm count, haemorrhage area and exudate area are shown in Tables 1-3.
The intra and interobserver coefficients of variation were greatest for the haemorrhage area, especially in those patients with a large area of haemorrhage. This is probably due to indefinite or blurred borders, making accurate definition difficult. As the square root of the areas are used in the index, the effect of the variability is reduced.

The intraobserver coefficient of variation for the microaneurysm count ranged from 7-14\%, with an interobserver variation of $13 \%$. A linear relationship was found between microaneurysm new events appearing in the previous year and total microaneurysm counts (Fig. 4). New events accounted for $70 \%$ of the total $\mathrm{mh}$ count.

The variation with time in the individual features quantified (Fig.5) show a trend towards retinal deterioration over a two year period in the 69 patients studied.

Regional differences on the retina are detailed in Table 4. Microaneurysms and areas of haemorrhage were found to occur most frequently in the temporal to 


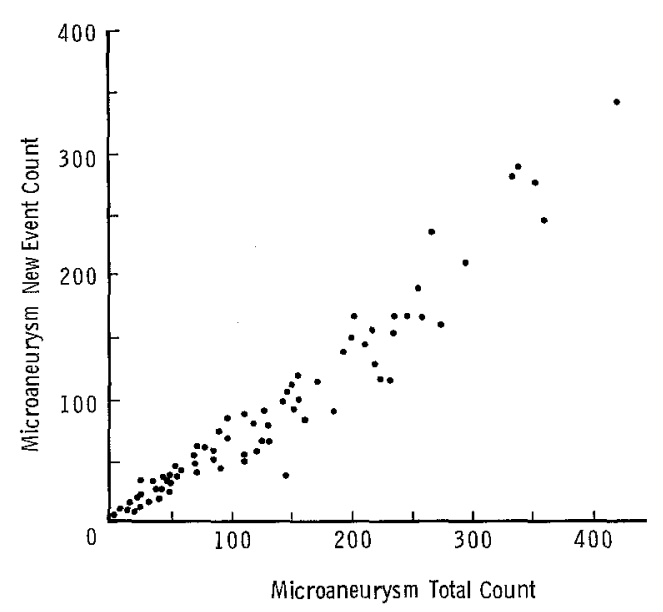

Fig.4. The results of 69 patients with year 1 total microaneurysm count (abscissa) and year 1 new microaneurysm event count (ordinate) showing a linear relationship

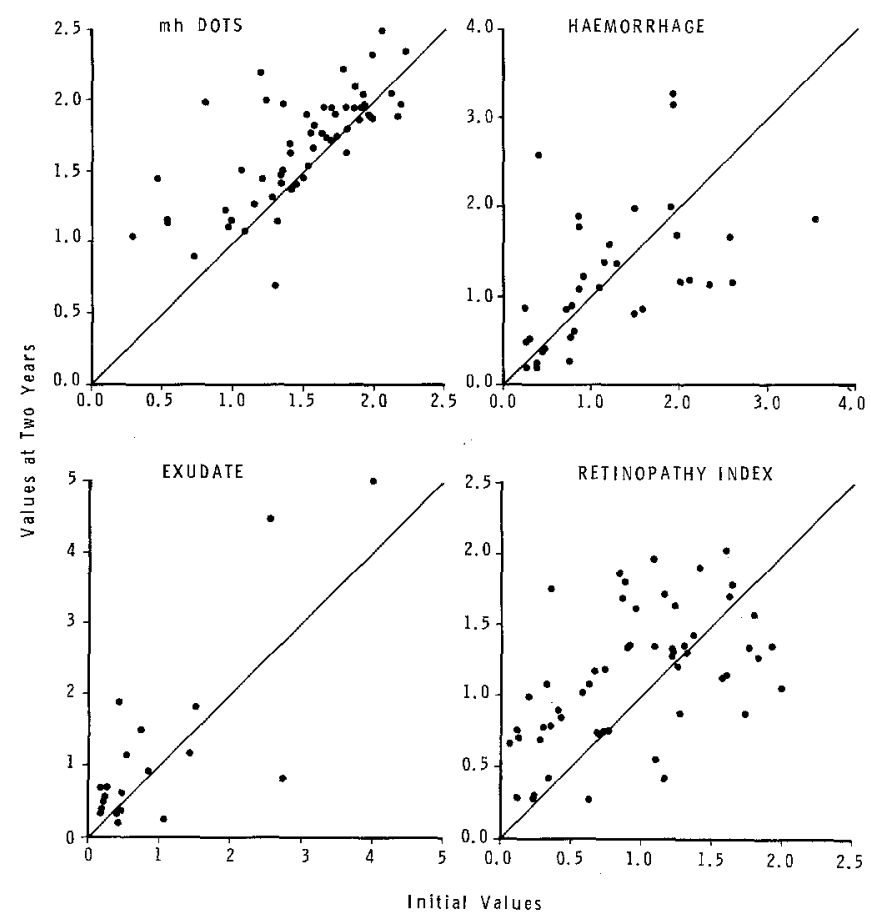

Fig. 5. Comparison of microaneurysms ( $m$ h dots, $\log _{10}$ ), haemorrhage area (square root), exudate area (square root) and Retinopathy Index in 69 Type 1 diabetic patients with background retinopathy, with initial visit (abscissa) and two years later (ordinate). A trend towards deterioration is seen for mh dots, exudate and the Retinopathy Index macula field and secondly in the macular area. Exudates occurred most commonly at the macula, whilst cotton wool spots were found slightly more frequently on the nasal side of the retina.

\section{Discussion}

Quantitation of individual features of standard retinal photographs allows small changes in diabetic retinopathy to be assessed over relatively short time periods. The method is useful in studying early retinopathy in intervention studies. The traditional methods such as the Hammersmith Grading or Airlie House grading are more suited to gross retinopathic changes in moderate and severe retinopathy, and will inevitably be less sensitive or require longer followup to establish a significant change. Thus, $80 \%$ of the 69 patients studies had, by the Hammersmith Grading, a grade of less than slide B for haemorrhage; $100 \%$ had a grade of less than slide B for exudate. The modified Airlie House, Wisconsin 191 method [10], has six levels of retinopathy. The presence of microaneurysms alone is graded as " 2 " and is unaffected by an increase in number of microaneurysms. More clinical attention is being paid to therapy of patients with early retinopathy, and a suitable method of quantitation is needed. Whilst we found projection of the photographs onto a screen for quantitation by hand simple and effective, if desired the photographs could be projected onto a digitisation screen for computerbased quantitation [11]. Different grading and quantitation systems are compared in Table 5.

By producing a montage from composite fields, the problems of overlapping fields and counting lesions more than once is obviated. Each feature is only noted once in its correct position. The feature may appear on two fields, which may help to identify doubtful lesions. In addition, a single montage on a clear acetate sheet is produced for each eye so that changes in subsequent years are readily identified by overlaying the acetate sheets. It is therefore possible to quantify new events as well as the total number of events. The direct measurement technique allows all visible lesions to be assessed and recorded, although for statistical purposes only a selected portion of the retina is photographed. The use

Table 4. Sector by sector analysis of individual retinal features in 69 Type 1 diabetic patients found to have background retinopathy on screening

\begin{tabular}{llllllr}
\hline & $\begin{array}{l}\text { Superior } \\
\text { temporal }\end{array}$ & $\begin{array}{l}\text { Superior } \\
\text { nasal }\end{array}$ & $\begin{array}{l}\text { Nasal to } \\
\text { disc }\end{array}$ & $\begin{array}{l}\text { Inferior } \\
\text { nasal }\end{array}$ & $\begin{array}{l}\text { Inferior } \\
\text { temporal }\end{array}$ & $\begin{array}{l}\text { Macula } \\
\text { Temporal } \\
\text { to macula }\end{array}$ \\
\hline $\begin{array}{l}\text { Mean microaneur- } \\
\text { ysm count }\end{array}$ & 6.0 & 5.4 & 7.3 & 4.5 & 4.3 & 9.9 \\
$\begin{array}{l}\text { Mean haemorrhage } \\
\text { area }\left(\mathrm{mm}^{2}\right)\end{array}$ & 0.22 & 0.24 & 0.30 & 0.29 & 0.33 & 0.37 \\
$\begin{array}{l}\text { Mean exudate area } \\
\left(\mathrm{mm}^{2}\right)\end{array}$ & 0.04 & 0.03 & 0.09 & 0.01 & 0.05 & 0.33 \\
$\begin{array}{l}\text { Mean cotton wool } \\
\text { spot count }\end{array}$ & 0.09 & 0.15 & 0.09 & 0.11 & 0.07 & 0.21 \\
\hline
\end{tabular}


Table 5. A comparison of different methods of quantitation and grading of diabetic retinopathy

\begin{tabular}{|c|c|c|c|c|c|c|c|c|c|}
\hline & $\begin{array}{l}\text { Comparison } \\
\text { with standard } \\
\text { photographs }\end{array}$ & $\begin{array}{l}\text { Grade } \\
\text { or } \\
\text { count }\end{array}$ & \multicolumn{4}{|c|}{ Retinal features quantitated } & Precision & $\begin{array}{l}\text { Applicable } \\
\text { severity of } \\
\text { retinopathy }\end{array}$ & $\begin{array}{l}\text { Initial } \\
\text { use of } \\
\text { method }\end{array}$ \\
\hline $\begin{array}{l}\text { Hammersmith } \\
\text { Oakley et al. } 1967\end{array}$ & Yes & Grade & $\mathrm{com} 1$ & ined & & & $\begin{array}{l}\text { Approximate } \\
\text { grading }\end{array}$ & severe & $\begin{array}{l}\text { Effects of pitu- } \\
\text { itary ablation }\end{array}$ \\
\hline $\begin{array}{l}\text { Airlie House } \\
\text { Goldberg et al. } \\
1969\end{array}$ & Yes & Grade & $\sqrt{ }$ & $\begin{array}{l}V \quad V \\
\text { combined }\end{array}$ & $\begin{array}{l}V \\
\text { combined }\end{array}$ & $\begin{array}{l}V \quad V \\
\text { combined }\end{array}$ & $\begin{array}{l}\text { Detailed } \\
\text { grading }\end{array}$ & $\begin{array}{l}\text { moderate } \\
\text { and severe }\end{array}$ & $\begin{array}{l}\text { Photo- } \\
\text { coagulation of } \\
\text { new vessels }\end{array}$ \\
\hline $\begin{array}{l}\text { Point counting } \\
\text { Parr and Spears } \\
1972\end{array}$ & & Count & comb & ined & & & Quantitation & moderate & \\
\hline $\begin{array}{l}\text { Fluoroscein } \\
\text { micro- } \\
\text { aneurysm count } \\
\text { Baudoin et al } \\
1983\end{array}$ & & Count & V & & & & $\begin{array}{l}\text { Quantitation } \\
\text { of fluoroscein } \\
\text { angiograms }\end{array}$ & early & $\begin{array}{l}\text { Prospective } \\
\text { Study of Aspirin } \\
\text { over } 2 \text { yrs }\end{array}$ \\
\hline $\begin{array}{l}\text { Wisconsin } 191 \\
\text { Klein et al. } \\
1984\end{array}$ & Yes & Grade & $\checkmark$ & $\begin{array}{l}V \quad V \\
\text { combined }\end{array}$ & $\begin{array}{l}V \\
\text { combined }\end{array}$ & $\begin{array}{l}V \\
\text { combined }\end{array}$ & $\begin{array}{l}\text { Detailed } \\
\text { grading, } \\
\text { combined for } \\
\text { prognostic } \\
\text { significance }\end{array}$ & $\begin{array}{l}\text { moderate } \\
\text { and severe }\end{array}$ & $\begin{array}{l}\text { Progression } \\
\text { of retinop- } \\
\text { athy over a } 6 \mathrm{yr} \\
\text { period }\end{array}$ \\
\hline $\begin{array}{l}\text { Colour photo- } \\
\text { graph quantita- } \\
\text { tion with Retinop- } \\
\text { athy Index } \\
\text { Howard-Williams } \\
\text { et al. } 1986\end{array}$ & & Count & $\checkmark$ & $\sqrt{ }$ & $\sqrt{ }$ & & $\begin{array}{l}\text { Detailed } \\
\text { quantitation }\end{array}$ & $\begin{array}{l}\text { early and } \\
\text { moderate }\end{array}$ & $\begin{array}{l}\text { Prospective } \\
\text { Study of diabe- } \\
\text { tes control over } \\
2 \text { yrs }\end{array}$ \\
\hline
\end{tabular}

$\mathrm{ma}=$ microaneurysms, $\mathrm{hm}=$ haemorrhages, he $=$ hard exudates, cws $=$ cotton wool spots, irma $=$ intra retinal microvascular abnormalities, $\mathrm{nv}=$ neovascularisation, prolif $=$ proliferation

of additional stereoscopic photographs would help to identify macular oedema or drusen. Most drusen would not be included as hard exudates, as only those larger than $110 \mu$ diameter are quantitated. Analysis by sector or zone of interest, e.g. macula, may show behaviour which is representative of the whole retina and may in time reduce the amount of retina which needs to be observed in detail. The finding that exudates occur more commonly at the macula, whilst cotton wool spots are more frequent on the nasal side of the retina, supports the observations of Kohner [5]. Davis [12] noted the frequent occurrence of microaneurysms, temporal to the macula, in background retinopathy.

The high turnover of microaneurysms, with $70 \%$ having appeared in the previous year at all severities of retinopathy, means that little is gained from counting "new events" rather than the total microaneurysm count.

Parr and Spear [13] have devised a method of point counting features from red-free retinal photographs which, although more accurate than comparisons with standard reference slides, can produce sampling inaccuracies. The detection of diabetic retinopathy by colour photography and fluorescein angiography has been investigated by several workers. Frank et al. [14] studied
166 diabetic patients and found significantly more retinopathy with angiography as compared with colour photographs $(18 \% \vee 11 \%, p=0.01)$ as did Malone et al. [15] (77\% v 14\%, $p=0.001)$. However, Palmberg et al. [16] found no significant difference $(41 \%$ v $42 \%)$. Baudoin et al. [17] have described a method for quantifying microaneurysms from fluorescein angiograms. Fluorescein angiography has the advantage of allowing differentiation between microaneurysms and small microhaemorrhage and allowing identification of areas of peripheral ischaemia. However, it is an invasive technique which is not acceptable to all patients. For accurate quantification, fluorescein angiograms must be of a very high standard with good capillary detail, which may be difficult to obtain on some patients or may require repeating. Comparing results from year to year can pose a problem in matching up the same phase of the angiograms. A precise means of assessing colour photographs may be as effective.

Combining the individual retinopathic features seen on colour photographs as a Retinopathy Index simplifies comparison of retinopathy with other measures of diabetes, e.g. metabolic parameters, and is helpful in assessing retinopathy in prospective studies [3]. Whilst it is possible that different aspects of the retinopathy may, to 
a certain extent, be affected by different pathological factors, in general all features become more common with increasing retinopathy. The statistical interdependence of the different features can be used to combine quantitation of each of them into a single index of retinopathy. This automatically provides a differing scaling for each feature. For example, cotton wool spots are regarded as being pre-proliferative, and the index is in accord with this, one cotton wool spot being the equivalent of 70 microaneurysms. The relative weightings are derived from the inital data set rather than being a clinical assessment as used in the Wisconsin "191" grading. Combining all features as an index lessens the dependence on any one feature. Thus, reliance on microaneurysm count alone can be misleading, as a lower count might paradoxically be due to reduced retinal perfusion, but this would usually be detected by worsening of other features. The use of a single index avoids multiple statistical analyses of several different retinal variables which may lead to Type I statistical errors in prospective studies. The use of an index does not prevent evaluation of specific features where appropriate.

Acknowledgements. We are grateful to the Wellcome Trust for a grant; Ms A.Smith and Ms B.Smith for computer analyses, Mr. D. Barbour for photographic and Ms J. Steemson for nursing assistance.

\section{References}

1. Goldberg MF, Fine SL (1969) Symposium on the treatment of diabetic retinopathy. US Department of Health, Education \& Welfare, Washington DC, pp 7-15

2. Oakley N, Hill DW, Joplin GF, Kohner E, Fraser TR (1967) Diabetic retinopathy. I. The assessment of severity and progress by comparison with asset of standard fundus photographs. Diabetologia 3: 402-405

3. Holman RR, Dornan TL, Mayon-White V, Howard-Williams J, Orde-Peckar C, Jenkins L, Steemson J, Rolfe R, Smith B, Barbour D, McPherson K, Poon PYW, Rizza C, Mann JI, Knight AH, Bron AJ, Turner RC (1983) Prevention of deterioration of renal and sensory nerve function by more intensive management of insulin-dependent diabetics: a two year randomised prospective study. Lancet 1 : 204-8

4. Taylor E, Jennings A (1971) Calculation of the total retinal area. $\mathrm{Br}$ J OphthaImol 55: 262-265

5. Kohner EM (1969) The vascular lesions of diabetic retinopathy. Their natural history and the effect of diabetic control and pituitary ablation on their progression. MD thesis. London
6. Kohner EM, Dollery CT (1970) The rate of formation and disappearance of microaneurysms in diabetic retinopathy. Eur $\mathrm{J}$ Clin Invest 1: 167-171

7. Friedenwald JS (1950) Diabetic retinopathy. Am J Ophthalmol 33: 1187-1199

8. Norton EWD, Gutman F (1967) Fluorescein angiography of the retina in diabetes mellitus. In: Kimura SJ, Caygill WW (eds) Vascular complications of diabetes mellitus, with special emphasis on microangiopathy of the eye. CV Mosby Co, St Louis, pp 120-138

9. Peckar CO (1983) The quantification of diabetic retinopathy. M Sc thesis, Oxford

10. Klein BEK, Davis MD, Segal P, Long JA, Harris A, Haug GA, Malgi YL, Syrjala S (1984) Diabetic retinopathy. Assessment of severity and progression. Ophthalmology 91: 10-17

11. Sleightholm MA, Arnold J, Aldington SJ, Kohner EM (1984) Computer-aided digitisation of fundus photographs. Clin Phys Physiol Meas 5: 295-301

12. Davis MD (1967) The natural course of diabetic retinopathy. In: Kimura SJ (ed) Vascular complications of diabetes with special emphasis on microangiopathy of the eye. CV Mosby, St Louis, pp 139-169

13. Parr JC, Spears GFS (1972) Grading of diabetic retinopathy by point-counting on a standardised photographic sample of the retina. Am J Ophthalmol 74: 459 465

14. Frank RN, Hoffman WH, Podger MJ (1982) Retinopathy in juveline-onset type I diabetes of short duration. Diabetes $31: 874-882$

15. Malone JI, van Cader TC, Edwards WC (1977) Diabetic vascular changes in children. Diabetes 26: 673-679

16. Palmberg P, Smith M, Waltman S, Krupin T, Singer P, Burgess D, Wendklant T, Achtenberg J, Cryer P, Santiago J, White N, Kilo C; Daughaday W (1981) The natural history of retinopathy in insulin-dependent juvenile-onset diabetes. Ophthalmology 88: 613-618

17. Baudoin C, Maneschi F, Quentel G, Soulrane G, Hayes T, Jones G, Coscas G, Kohner EM (1983) Quantitative Evaluation of Fluorescein Angiograms: Microaneurysm Counts. Diabetes [Suppl 2] 32: $8-13$

18. Kohner EM, Sleightholm M, The Kroc Collaborative Study Group (Appended) (1986) Does Microaneurysm Count Reflect Severity of Early Diabetic Retinopathy? Ophthalmology 93: 586-589

Received: 3 June 1985

and in revised form: 23 September 1986

Dr. J. R. Howard-Williams

Diabetes Research Laboratories

Radcliffe Infirmary

Woodstock Road

Oxford

$\mathrm{OX} 26 \mathrm{HE}$

UK 